\title{
APPLICATION OF KTH METHOD FOR DETERMINATION OF LATVIAN GEOID MODEL
}

\author{
Inese Janpaule ${ }^{1}$ \\ ${ }^{1}$ Department of Geomatics, Riga Technical University, Azzenes Str. 16/20, LV-1048 Riga, Latvia \\ E-mail: ${ }^{1}$ inesej@inbox.lv (correspondingauthor)
}

\begin{abstract}
The geoid calculation method by KTH was developed at the Royal Institute of Technology (KTH) in Stockholm and it is based on the modified version of Stoke's formula. The initial phase of experimental gravimetric geoid computations in the territory of Latvia by KTH method used digital free air anomaly data from the USSR era and the data from EGM2008 - global Earth's gravitational field model. Also the data from the gravimetric measurements of Latvian Geospatial information agency for the region of Riga were used and EGM2008 data as well as the data from GO_CONS_GCF_2_DIR_R4 - Earth's gravitational field model obtained by GOCE satellite. The mean square error for the geoid model in the region of Riga, obtained using this most recent data from gravimetric measurements and GO_CONS_GCF_2_DIR_R4, according to the GNSS/levelling data is equal to $7.5 \mathrm{~cm}$.
\end{abstract}

Keywords: gravimetric geoid, KTH method, Stoke's formula, global geopotential model.

\section{Introduction}

The geoid calculation method by KTH was developed at the Royal Institute of Technology (KTH) in Stockholm (Sjöberg 1986, 1991, 2003a, 2003b). The practical application of the KTH method is explained by (Agren 2004). This method uses the least squares modification of the Stoke's integral. The modified Stoke's formula approach has already been used for regional gravimetric geoid determination in the Baltic countries by (Ellmann 2005). In KTH approach the modified integral combines the regional terrestrial gravity data with global geopotential model (GGM) data. Four corrections are calculated and applied to the approximate geoid heights in order to obtain final gravimetric geoid heights. These four corrections refer to the effect of downward continuation (DWC) reduction, the topographic and atmospheric effects, and the formulation of the Stoke's integral in the spherical approximation. KTH method has been successfully used to compute new geoid models and evaluate the existing geoid models in several countries (Abdalla, Tenzer 2010, Kiamehr 2006).

The objective of this work was to calculate the geoid model for the territory of Latvia and Riga Region applying the KTH method using the available garvimetric data and most recent and reliable GGM data. Firstly experimental gravimetric geoid computations were made using digitised free air anomaly data from the USSR era and data from EGM2008 - global Earth's gravitational field model. Second part of the work was done using recent gravimetric measurements of Latvian Geospatial information agency for the region of Riga and EGM2008 data as well as the data from GO_CONS_GCF_ 2_DIR_R4 - Earth's gravitational field model obtained by GOCE satellite.

The obtained geoid models were then compared with Latvian gravimetric geoid model LV'98 (Kaminskis 2010). Appropriate transformation was applied to the Riga Region geoid models because the global geopotential models are not fitted to the national height system. The transformation was not applied to the geoid model for the territory of Latvia where the digitised free air anomaly data was used because this model was experimental.

\section{Computation of the experimental gravimetric geoid model}

The input data used for the computation of approximate geoid height:

1. ICGEM (International Centre for Global Gravity Field Models) global Earth's gravitational field model EGM2008 up to degree 360, 180 or 120 of spherical harmonics;

2. Free air gravity anomalies from Nordic Geodetic Commission gravimetric data base (Figure 1). These free air gravity anomalies have been digitised from old former USSR era free air gravity anomaly maps for the territory of Latvia. This data was extrapolated to a $0.1 \times 0.2$ arc-degree grid in the area bounded by the parallels of 55.4 and 58.6 arc-degree northern latitude and the meridians of 20.8 and 29.0 arcdegree eastern longitude.

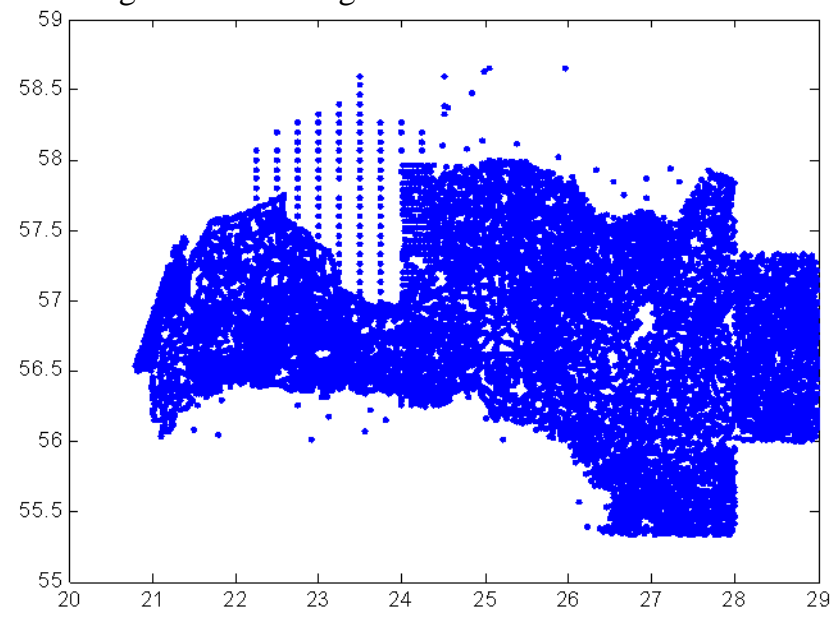

Fig. 1. Free air gravity anomaly data coverage form Nordic Geodetic Commission gravimetric data base.

The input data used for the computation of four corrections:

1. SRTM (Shuttle Radar Topography Mission) digital height model from U.S. Geological Survey;

2. Free air gravity anomalies from Nordic Geodetic Commission gravimetric data base (same as previous step); 
3. Approximate height anomalies from ICGEM calculation service, EGM2008 model.

Various solutions were applied in the KTH method to estimate the optimal spherical integration radius and spherical harmonic degree of the GGM coefficients. Approximate geoid height and corrections were computed using spherical integration radius with values: $3,1,0.5$, 0.25 and 0.1 degree and maximum spherical harmonics degree of the GGM coefficients: 360, 180, 120.

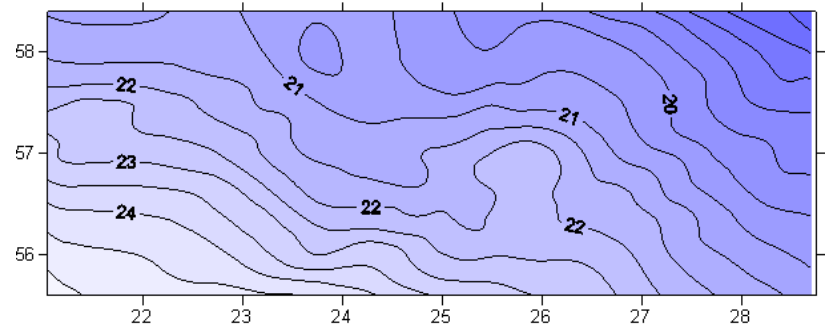

Fig. 2. Obtained approximate geoid height using EGM2008 up to degree 360 and spherical integration radius of 0.1 degree [m].

The topographic correction is shown in Figure 3a. It varies from $-8 \mathrm{~mm}$ to $0 \mathrm{~mm}$ with the mean of $-1 \mathrm{~mm}$, and the standard deviation $1 \mathrm{~mm}$. Minimum value of DWC reduction is $-3 \mathrm{~mm}$, maximum value is $10 \mathrm{~mm}$, mean is $0.5 \mathrm{~mm}$, and the standard deviation is $1.5 \mathrm{~mm}$
(Fig. 3b.). Ellipsoidal correction varies from $0 \mathrm{~mm}$ to $1 \mathrm{~mm}$ with the mean of $0.9 \mathrm{~mm}$, and the standard deviation is $0.3 \mathrm{~mm}$ (Fig. 3c.). The atmospheric correction over the study area of Latvia is almost negligible; it is constant for the whole territory: $1 \mathrm{~mm}$. Minimum value of the sum of all corrections for the territory of Latvia is $-5 \mathrm{~mm}$, maximum value is $8 \mathrm{~mm}$, mean is $-1.1 \mathrm{~mm}$, and the standard deviation is $1.6 \mathrm{~mm}$ (Fig. 3d.), altogether four corrections give minimal contribution to approximate geoid height value changes.

Several versions of the Latvian geoid model were computed with different maximum spherical harmonics degrees of the GGM coefficients and spherical integration radius values using $\mathrm{KTH}$-Geolab software. Geoid model computations for the territory of Latvia were made using EGM2008 spherical harmonics coefficients up to degree 360 and spherical integration radius 0.1 degree, 0.25 degrees and 0.5 degrees, using EGM2008 spherical harmonics coefficients up to degree 180 and spherical integration radius 0.1 degree, 0.25 degrees and 3 degrees, and using EGM2008 spherical harmonics coefficients up to degree 120 and spherical integration radius 0.1 degree, 0.25 degrees and 3 degrees. Results are shown in Table 1 . a)

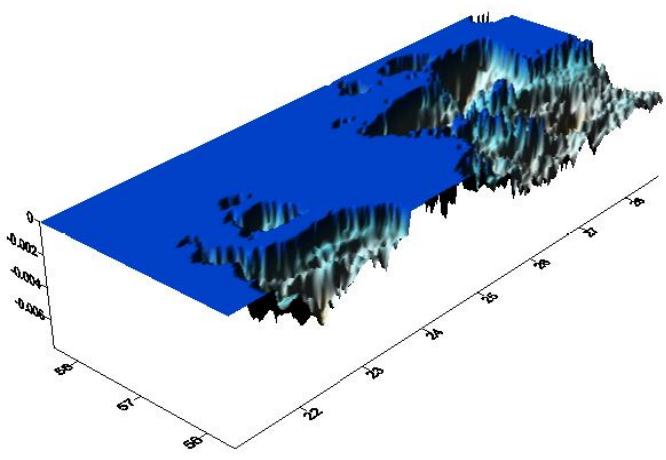

b)

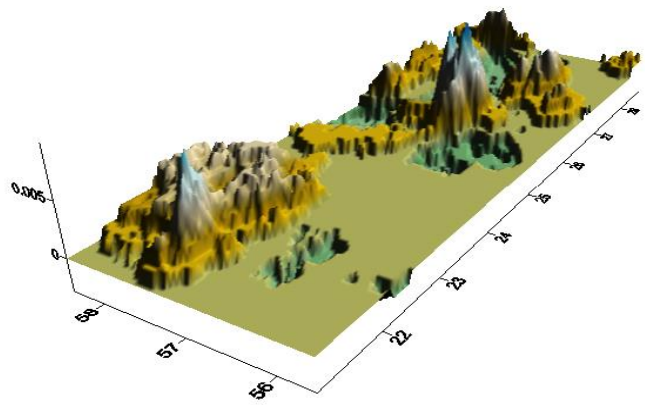

d)

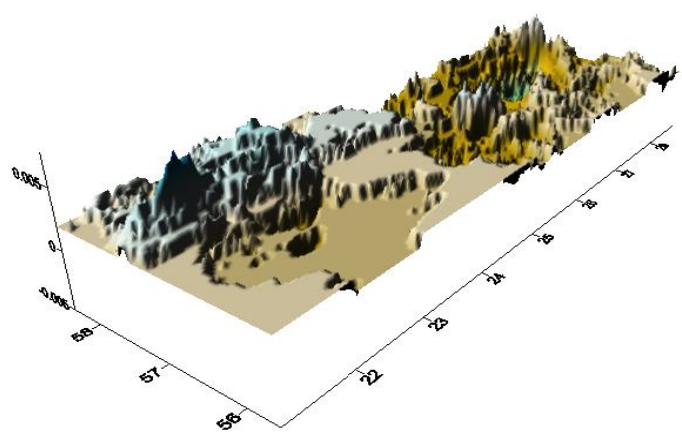

c)

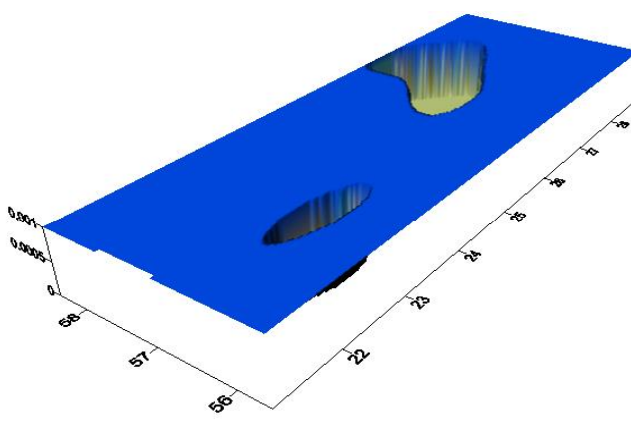

Fig. 3. Corrections to the approximate geoid heights using EGM2008 up to degree 360 and spherical integration radius of 0.1 degree: a) topographic correction, b) downward continuation correction, c) ellipsoidal correction, d) sum of all corrections for the territory of Latvia. 
Table 1. Comparison of the Latvian geoid model LV'98 heights with geoid model heights obtained using KTH-Geolab software.

\begin{tabular}{|c|c|c|c|c|c|}
\hline GGM degree & $\begin{array}{c}\text { Spherical integration } \\
\text { radius (degree) }\end{array}$ & Min $(\mathrm{m})$ & $\operatorname{Max}(\mathrm{m})$ & $\operatorname{Mean}(\mathrm{m})$ & $\begin{array}{c}\text { Std.dev. } \\
(\mathrm{m})\end{array}$ \\
\hline EGM2008 360 & $\mathbf{0 . 1}$ & $\mathbf{- 1 . 3 9}$ & $\mathbf{0 . 4 1}$ & $\mathbf{- 0 . 4 6}$ & $\mathbf{0 . 2 9}$ \\
\hline EGM2008 360 & 0.25 & -1.75 & 0.81 & -0.46 & 0.43 \\
\hline EGM2008 360 & 0.5 & -2.49 & 1.61 & -0.48 & 0.76 \\
\hline EGM2008 180 & 0.25 & -2.21 & 1.20 & -0.48 & 0.58 \\
\hline EGM2008 180 & 1 & -2.69 & 1.83 & -0.51 & 0.90 \\
\hline EGM2008 180 & 3 & -3.68 & 1.97 & -0.78 & 1.19 \\
\hline EGM2008 120 & 0.25 & -2.49 & 1.34 & -0.47 & 0.70 \\
\hline EGM2008 120 & 1 & -2.77 & 1.92 & -0.52 & 0.96 \\
\hline EGM2008 120 & 3 & -3.60 & 1.98 & -0.77 & 1.18 \\
\hline
\end{tabular}

To evaluate precision of the obtained geoid models, comparison with the Latvian geoid model LV'98 was carried out. Relatively best result was obtained using EGM2008 spherical harmonics coefficients up to degree 360 and spherical integration radius 0.1 degree, minimum value of comparison is $-1.39 \mathrm{~m}$, maximum value is $0.41 \mathrm{~m}$, mean is $-0.4586 \mathrm{~m}$, and the standard deviation is $0.2873 \mathrm{~m}$.

Some authors (Liu 2008, Wahr 2008) demonstrate that the best results are achieved using spherical integration radius 3 degrees, but the obtained geoid models show that results are improving while reducing spherical integration radius. It could be explained with the fact that the relief in the territory of Latvia is mostly flat or slightly hilly, and these forms of relief do not exert a significant influence on the gravity field, hence larger spherical integration radius does not improve geoid height results.

\section{Computation of gravimetric geoid model of Riga Region}

Due to the possibility to receive gravimetric measurement data (gravimetric point number, geodetic coordinates on GRS80 ellipsoid, Earth gravity values reduced to the point in IGSN71 system, point normal height in BAS-77 system) from Latvian Geospatial Information Agency (LGIA) for Riga Region bounded by the parallels of $56^{\circ} 34^{\prime} 48^{\prime \prime}$ and $57^{\circ} 24^{\prime} 00^{\prime \prime}$ northern latitude and the meridians of $23^{\circ} 00^{\prime} 00^{\prime \prime}$ and $24^{\circ} 54^{\prime} 00^{\prime \prime}$ eastern longitude, computation for gravimetric Riga Region geoid model was carried out. Gr2 gravimetric points were systematically measured since 1999, but previously measurements were only occasional within Denmark and Baltic State cooperation programme "Latvian height analysis and modernisation". Precision of the received gravimetric measurement data is $0.03 \mathrm{mGal}$. Data coverage area and the estimated geoid height area are shown in Figure 4.

Because free air gravity anomalies $\delta g_{F}$ were needed for geoid computation, Earth surface gravity values $\Delta g$ were reduced to free air gravity anomalies. Free-air anomaly is the measured gravity anomaly after a free-air correction is applied to correct for the elevation at which a measurement is made. The free-air correction does so by adjusting these measurements of gravity to what would have been measured at sea level. For this reduction gravity gradient vertical component in free air

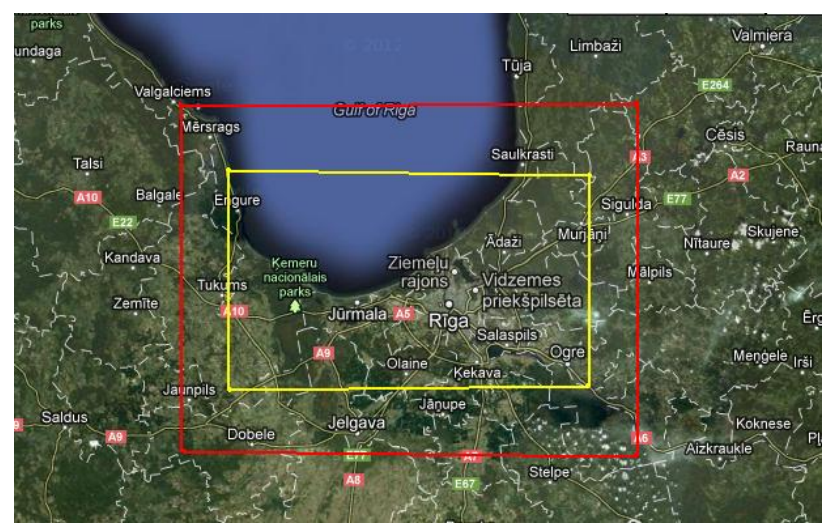

Fig. 4. Gravimetric data area (red line) and estimated geoid height area (yellow line).

$\frac{\partial g}{\partial H}$ and orthometric height $H$ are used. Comparison with normal gravity $\gamma_{0}$ gives:

$$
\Delta g_{F}=\Delta g+\partial g_{F}-\gamma_{0}
$$

Free air reduction $\partial g_{F}$ is included using normal vertical gradient $\frac{\partial \gamma}{\partial h}$, its value $3086 \mathrm{~ns}^{-2}$ for geographical latitude $\varphi=45^{\circ}$ is sufficient:

$$
\partial g_{F}=-\frac{\partial g}{\partial H} H \approx-\frac{\partial \gamma}{\partial h} H \approx 3.086 H_{(m)} \mu m s^{-2}
$$

Normal gravity on the ellipsoid $\gamma_{0}$ was obtained using Somigliana formula:

$$
\gamma_{0}=\frac{a \gamma_{a} \cos ^{2} \varphi+b \gamma_{b} \sin ^{2} \varphi}{\sqrt{a^{2} \cos ^{2} \varphi+b^{2} \sin ^{2} \varphi}}
$$

where $a$ is semimajor axis, $b$ is semiminor axis of ellipsoid, $\gamma_{a}$ is normal gravity on equator, $\gamma_{b}$ is normal gravity on poles (Torge 1991).

For the computation of Riga Region geoid model EGM2008 spherical harmonics coefficients up to degree 360 and spherical integration radius 0.1 degree were used. After KTH-Geolab computation process 7 parameter transformation (Kotsakis, Sideris 1999) was 
applied using $13 \mathrm{GNSS} /$ levelling data points. To evaluate the accuracy of the obtained geoid model the remaining GNSS/levelling data points located in Riga Region were used for quality control, 19 points overall. According to those points maximum residual value is $12.5 \mathrm{~cm}$, minimum is $2.4 \mathrm{~cm}$, mean is $6.9 \mathrm{~cm}$ and standard deviation is $7.5 \mathrm{~cm}$. Comparison with the Latvian geoid model LV'98 is shown in Figure 5.

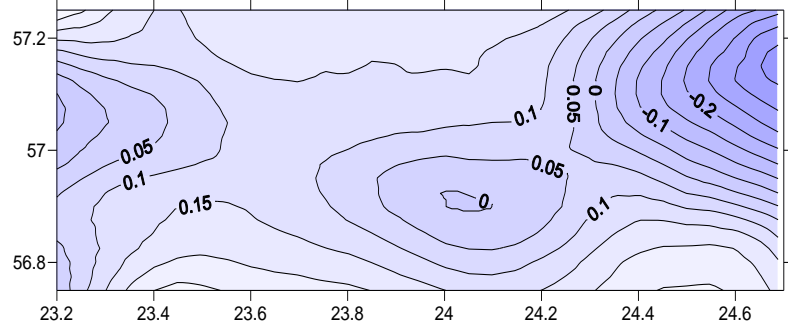

Fig. 5. LV'98 and KTH EGM2008 geoid height comparison for solutions in the region of Riga [m].

Minimum residual value of comparison is $-0.379 \mathrm{~m}$, maximum value is $0.298 \mathrm{~m}$, mean is $0.075 \mathrm{~m}$ and standard deviation is $0.121 \mathrm{~m}$. The largest residuals can be observed in Riga Gulf region, it can be explained by the lack of gravimetric measurements in this region (Jürgenson et.al. 2008). Residuals can be observed also in the North-East and West parts of the region.

One more test computation of Riga Region geoid model was carried out using GOCE GO_CONS_ GCF_2_DIR_R4 (Dahle et.al. 2012) spherical harmonics coefficients up to degree 260 and spherical integration radius 0.1 degree. GO_CONS_GCF_2_DIR_R4 is the latest model from GOCE satellite models. After KTHGeolab computation process 7 parameter transformation was applied using $13 \mathrm{GNSS} /$ levelling data points in Riga Region. To evaluate the accuracy of the obtained geoid model the remaining GNSS/levelling data points from Riga Region were used for quality control, 21 points overall. According to those points maximum residual value is $4.2 \mathrm{~cm}$, minimum is $-8.7 \mathrm{~cm}$, mean is $3.0 \mathrm{~cm}$ and standard deviation is $5.0 \mathrm{~cm}$. Comparison with the Latvian geoid model LV'98 is shown in Figure 6.

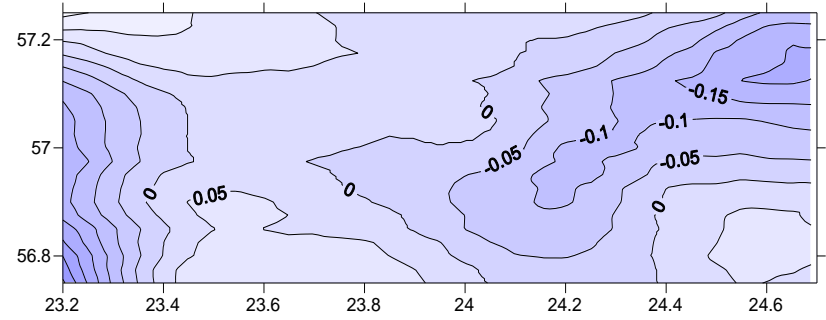

Fig. 6. LV'98 and KTH GO_CONS_GCF_2_DIR_R geoid height comparison for solutions in the region of Riga [m].

Minimum residual value of comparison is $-0.359 \mathrm{~m}$, maximum value is $0.165 \mathrm{~m}$, mean is $0.020 \mathrm{~m}$ and standard deviation is $0.078 \mathrm{~m}$. As in the previous comparison with LV'98, residuals can be observed in the North-East and West parts of the region, while conformity in Riga Gulf region is reasonable. It can be concluded that in the region of Riga the compatibility of
GOCE GO_CONS_GCF_2_DIR_R4 is better than that of EGM2008 model.

\section{Conclusions}

With the use of KTH for gravimetric geoid calculations for the entire territory of Latvia, initially using the digital data of free air anomalies from the USSR area and data of global Earth's gravitational field model by EGM2008, a higher result than that with the mean square error of $28 \mathrm{~cm}$ was not obtained. The application of the most recent gravimetric measurement data from the Geospatial Information Agency of Latvia for the region of Riga and the data of EGM2008 data yielded a geoid model for the region of Riga with a higher degree of precision, the mean square error of which according to the GNSS/levelling point data was $7.5 \mathrm{~cm}$. The use of most recent gravimetric measurement data and the Earth's gravitational field model data from GOCE satellite GO_CONS_GCF_2_DIR_R4 revealed that the mean square error according to GNSS/levelling point data was $5 \mathrm{~cm}$. Thus, in the region of Riga the compatibility of GOCE GO_CONS_GCF_2_DIR_R4 is better than that of EGM2008 model. It must be concluded that the quality of historical gravimetric data restricts one from calculating a high quality geoid, but the density of actual gravimetric measurements accumulated by LGIA for Latvia as of yet is not sufficient.

\section{References}

Abdalla, A.; Tenzer, R., 2010. The evaluation of the New Zealand's geoid model using the KTH method. Geodesy and Cartography, 37(1), pp.5-14. http://dx.doi.org/10.3846/13921541.2011.558326

Agren, J., 2004. Regional Geoid Determination Methods for the Era of Satellite Gravimetry Numerical Investigations Using Synthetic Earth Gravity Models. Doctoral Dissertation in Geodesy. Stocholm: Royal Institute of Technology (KTH), Department of Infrastructure. $246 \mathrm{p}$.

Dahle, C.; Flechtner, F.; Gruber, C.; Koenig, D.; Koenig, R.; Michalak, G.; Neumayer, K.-H., 2012. GFZ GRACE Level-2 Processing Standards Document for Level-2 Product Release 0005. Scientific Technical Report-Data. Potsdam, 20 p.

Ellmann, A., 2005. Two deterministic and three stochastic modifications of Stokes's formula: A case study for the Baltic countries. Journal of Geodesy, 79(1-3), pp. 11-23. http://dx.doi.org/10.1007/s00190-005-0438-1

Jürgenson, H.; Liibusk, A.; Ellmann, A., 2008. Geoid profiles in the Baltic Sea determined using GPS and sea level surface. Geodezija ir Kartografija, 34(4), pp. 109-115.

Kaminskis, J., 2010. Geoid model for surveying in Latvia. In International FIG Congress 2010, FS 1C, 11-16 April, 2010, Sydney, Australia [online], [cited 23 August 2013]. Available at: www.fig.net/pub/fig2010/papers/fs01clfs01cka minskis_4066.pdf

Kiamehr, R., 2006. Precise Gravimetric Geoid Model for Iran Based on GRACE and SRTM Data and the Least-Squares Modification of Stokes' Formula with Some Geodynamic Interpretations. Doctoral Dissertation in Geodesy. Stocholm: Royal Institute of Technology (KTH), Department of Infrastructure. $89 \mathrm{p}$. 
Kotsakis, C.; Sideris, M.G., 1999. On the adjustment of combined GPS/levelling/geoid networks. Journal of Geodesy, 73(8), pp. 412-421. http://dx.doi.org/10.1007/s001900050261

Liu, X. 2008. Global gravity field recovery from satellite-tosatellite tracking data with the acceleration approach. Publications on Geodesy 68. Delft: Nederlandse Commissie voor Geodesie, 226 p.

Sjöberg, L. E., 1986. Comparison of some methods of modifying Stokes' formula. Boll. Geod. Sci. Aff., 46(2), pp. 229-248.

Sjöberg, L. E., 1991. Refined least squares modification of Stokes formula. Manusc.Geod, 16, pp. 367-375.

Sjöberg, L. E., 2003a. A computational scheme to model geoid by the modified Stokes formula without gravity reductions. Journal of Geodesy, 74, pp. 255-268.

Sjöberg, L.E., 2003b. A general model of modifying Stokes formula and its least squares solution. Journal of Geodesy, 77 , pp. 459-464.

http://dx.doi.org/10.1007/s00190-003-0346-1

Torge, W., 1991. Geodesy. 2nd Edition. Berlin, New York: Walter de Gruyter. 245 p.
Wahr, J., 2008. Time-Variable Gravity from Satellites. Department of Physics and Cooperative Institute for Research in Environmental Sciences. University of Colorado. Available at: http://www.gps.caltech.edu/classes/g e167/file/Wahr_Gravity_treatise.pdf

ICGEM Interntional Center for Global Gravity Field Models. Available at: http://icgem.gfz-potsdam.de/ICGEM/

Latvian Geospatial Information agency. Available at: http://www.lgia.gov.lv .

Nordic Geodetic Commision. Available at: http:// http://www.nkg.fi/

U.S. Geological Survey. Available at: http://www.usgs.gov

\section{Acknowledgements}

The research was funded by ERDF, project No 2010/0207/2DP/2.1.1.1.0/10/APIA/VIAA/077. The author wishes to thank Prof. J. Balodis for his advice and support during this research, Assoc. Prof. Dr. Cuneyt Aydin for introducing with KTH-Geolab software and giving the possibility to work with it, Latvian Geospatial Information Agency for providing the gravimetric measurement data. 